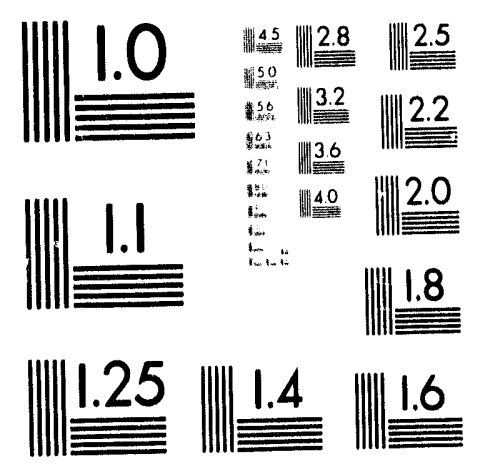



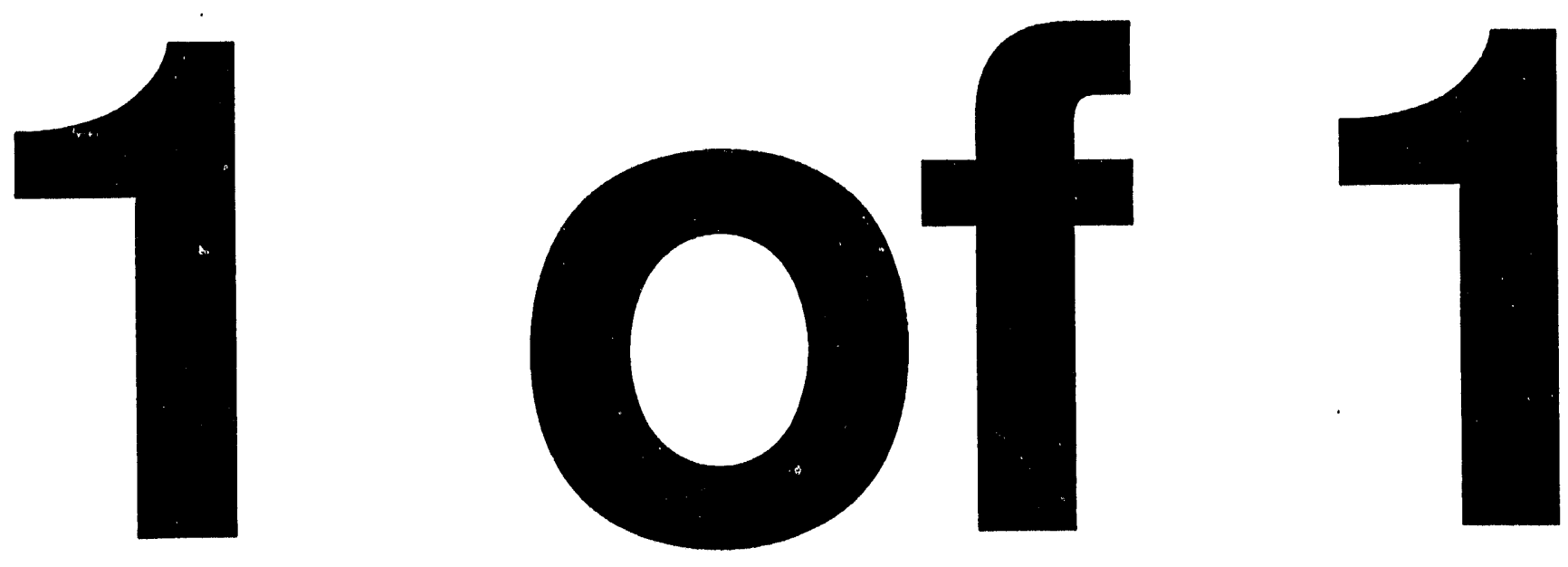
LA-UR- 93-3216

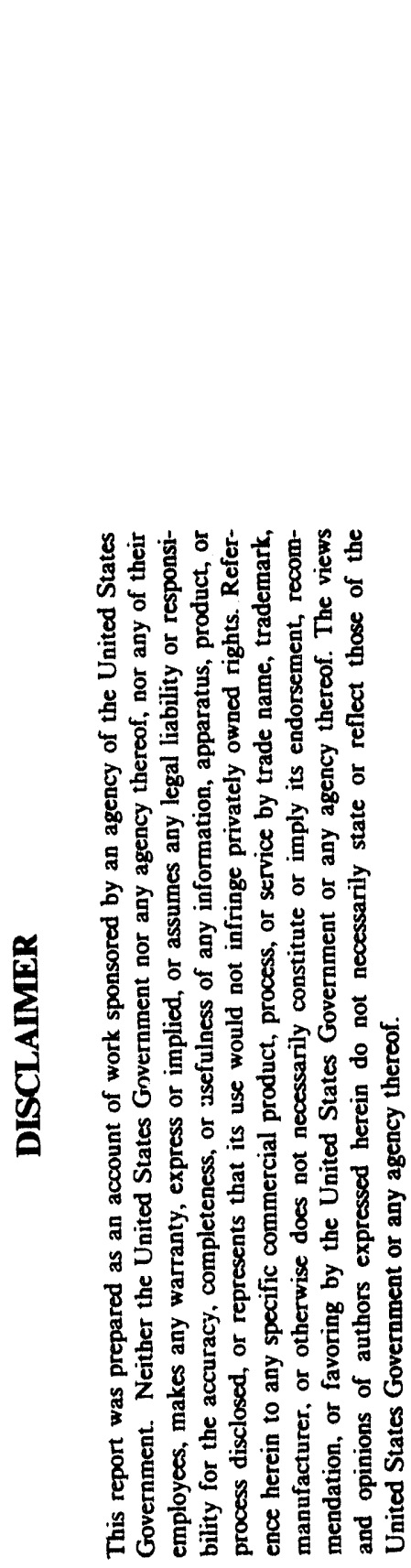

\section{Submitted to:}

\author{
Author(s): $\quad$ B. P. Wood \\ I. Henins \\ R. J. Gribble \\ W. A. Reass \\ R. J. Faeh1 \\ M. A. Nastasi \\ D. J. $\operatorname{Re} J$
} ION IMPLANTATION EXPERIMENT
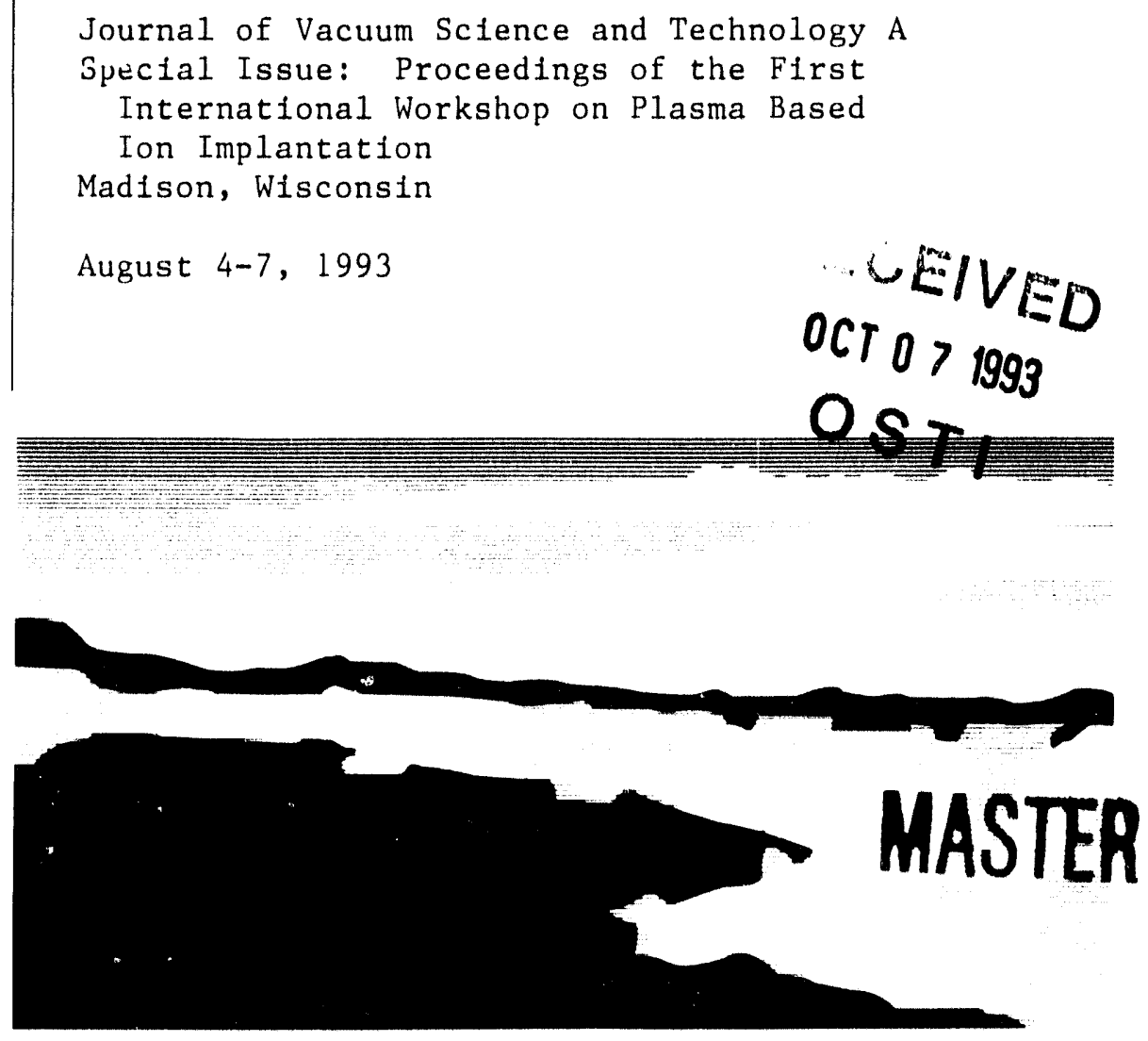

Los Alamos National Laboratory, an affirmative action/equal oppontunity emplojer, is operated by the University of California tor the U.S. Department of Energy under contract W.7405-ENG-36. By acceptance of this article, the publisher recognizes that the U S. Government retains a nonexclusive, royalty-free license to publish or reproduce the published torm of this contribution, or to allow olhers to do so. for U S Government purposes. The Los Alamos National Laboratory requests that the publisher identity this article as work performed under the auspices of the $\cup S$. Department of Energy. dre 


\title{
Initial Operation of a Large-Scale Plasma Source Ion Implantation Experiment
}

\author{
B. P. Wood, I. Henins, R. J. Gribble, W. A. Reass, \\ R. J. Faehl, M. A. Nastasi, and D. J. Rej \\ Los Alamos National Laboratory, Los Alamos, NM 87545
}

\begin{abstract}
In Plasma Source Ion Implantation (PSII), a workpiece to be implanted is immersed in a weakly ionized plasma and pulsed to a high negative voltage. Plasma ions are accelerated toward the workpiece and implanted in its surface. Experimental PSII results reported in the literature have been for small workpieces. A large-scale PSII experiment has recently been assembled at Los Alamos, in which stainless steel and aluminum workpieces with surface areas over $4 \mathrm{~m}^{2}$ have been implanted in a $1.5 \mathrm{~m}$-diameter, $4.6 \mathrm{~m}$-length cylindrical vacuum chamber. Initial implants have been performed at $50 \mathrm{kV}$ with $20 \mu$ s pulses of $53 \mathrm{~A}$ peak current, repeated at $500 \mathrm{~Hz}$, although the pulse modulator will eventually supply $120 \mathrm{kV}$ pulses of $60 \mathrm{~A}$ peak curreni at $2 \mathrm{kHz}$. A $1000 \mathrm{~W}, 13.56 \mathrm{MHz}$ capacitively-coupled source produces nitrogen plasma densities in the $10^{15} \mathrm{~m}^{-3}$ range at neutral pressures as low as 0.02 mtorr. A variety of antenna configurations have been tried, with and without axial magnetic fields of up to 60 gauss. Measurements of sheath expansion, modulator voltage and current, and plasma density fill-in following a pulse are presented. We consider secondary electron emission, $x$-ray production, workpiece arcing, implant conformality, and workpiece and chamber heating.
\end{abstract}




\section{Introduction}

The implantation of gaseous ions into metal surfaces creates a thin surface layer of modified material, resulting in increased hardness, reduced friction, improved wear, and corrosion resistance. Implantation is typically done by rastering an ion beam over the surface, although other plasma or liquid bath chemistry processes are sometimes used.

The process of Plasma Source Ion Implantation (PSII) was invented at the University of Wisconsin by Conrad $[1,2,3]$ as a simple, cost-effective alternative to conventional implantation processes. In PSII, a workpiece is immersed in a weakly ionized plasma containing the ions to be implanted. The workpiece is pulsed repeatedly to a high negative potential. During each pulse, the positive ions are accelerated toward the workpiece and implanted in its surface. Since the implant is performed over the entire surface simultaneously, high implant currents can be achieved, greatly reducing the total time required to treat an object. PSII eliminates the expensive, low current accelerators used to create the ion beam, and eliminates the need to mask or manipulate the workpiece, leading to a lower equipment cost than for conventional beam implanters.

In this paper we report on the design and initial ( peration of a large-scale PSII facility at Los Alamos National Laboratory, in which objects with surface areas over $4 \mathrm{~m}^{2}$ have been implanted. The experimental facility is described, and the system requirements and equipment constraints which underlie the design are summarized. The implications of these requirements and constraints for determining the operating point are discussed. Measurements of sheath expansion, modulator voltage and current, and plasma density fill-in following a pulse are presented. Finally, secondary electron emission, $\mathrm{x}$-ray production, implant conformality, workpiece arcing, and workpiece and chamber heating are discussed. 


\section{Experimental Facility and Design Constraints}

\subsection{Experimental facility}

The PSII experimental facility is built around a cylindrical, stainless steel vacuum chamber, $4.6 \mathrm{~m}$ in length and $1.5 \mathrm{~m}$ in diameter $\left(8 \mathrm{~m}^{3}\right.$ volume). The PSII chamber can be pumped to a base pressure of $10^{-6}$ torr by three turbomolecular pumps with a aggregate pumping rate of $1000 \mathrm{\ell s}^{-1}$. The turbo pumps are backed by a roots blower and forepurnp. A series of ports along the top, sides, and ends of the chamber allow diagnostic access and visual inspection. Twelve electromagnets, each of 14 turns, are installed coaxially around the chamber. Three of these magnets are grouped at each end. The electrical connections between the magnets can be varied, allowing mirror or cusp fields to be applied. Lead shielding will eventually be installed on and around the PSII chamber to shield $\mathrm{x}$-rays produced by energetic secondary electrons. The PSII chamber and electromagnets are shown in Figure 1.

Fixturing being constructed inside the PSII chamber will support workpieces weighing up to 7.5 tons, to be positioned using a 40 ton overhead crane. Inside the chamber, the workpiece sits on ceramic insulators similar to those used on highvoltage transmission lines.

A weakly ionized plasma of the implant species is established using a $1000 \mathrm{~W}$, $13.56 \mathrm{MHz}$ rf generator which is capacitively coupled to a $3 \mathrm{~cm}$ by $3.5 \mathrm{~m}$ stainless steel antenna running the length of the inside of the PSII chamber, hanging about $20 \mathrm{~cm}$ below the top. This antenna is supported at the middle by its electrical feedthrough. Using this plasma source, a discharge in the $10^{14}-10^{15} \mathrm{~m}^{-3}$ density range can be maintained in $\mathrm{N}_{2}$ to below 0.02 mtorr. Figure 2 shows the measured plasma density versus $r f$ power achieved with this plasma source at a variety of pressures. The plasma density is quite uniform in the empty chamber, varying by less than $\pm 10 \%$ throughout a $1 \mathrm{~m}$-diameter, $3 \mathrm{~m}$-length volume at $0.1 \mathrm{mtorr}$, a typical operating pressure.

A high-voltage modulator based on two Litton L-3408 hollow beam switch tubes is capable of supplying $60 \mathrm{~A}, 20 \mu$ s pulses at up to $120 \mathrm{kV}$ with a frequency of up to $2 \mathrm{kHz}$. To date, it has been operated only as high as $53 \AA, 50 \mathrm{kV}$, and $500 \mathrm{~Hz}$. The construction of the modulator has been described in detail elsewhere $[4,5]$. The 
modulator electronics is shown outside its oil tank in Figure 3.

The PSII process is controlled remotely by computer from the PSII control room via Modicon Programable Logic Control modules, which communicate via fiber optic cable with the modulator and other related support hardware. The control system monitors switching waveforms, and shuts off $\mathrm{AC}$ power to the modulator in the event of a fault. Faults include L-3408 arc-over, workpiece arcing, and pulse timing anomalies. In addition, the control system provides real time electrical diagnostics to the controlling computers, and controls the system interlocks. In the future it will control the rf plasma source and vacuum system. The control system is described in more detail in reference [6].

The modulator is connected to the workpiece via a low capacitance coaxial cable and a high-voltage vacuum feedthrough in the side of the PSII chamber.

\subsection{Design Constraints}

Even with over 50 Amperes of current available, the experiment is current-limited due to the requirement to implant large areas. To reduce the power dissipated inside the switch tubes, it is desirable to linit the voltage rise-time to $5 \mu \mathrm{s}$. This necessitates operating at a low plasma density-higher densities result in longer rise-times. $\mathrm{RF}$ plasma source powers of $100 \mathrm{~W}$ and plasma densities of $5 \times 10^{14} \mathrm{~m}^{3}$ are typical operating parameters. These low plasma densities result in large sheaths being formed. The jon flight across the sheath must be collisionless if the ions are to implanted at full energy. Maintaining a collisionless $30 \mathrm{~cm}$ sheath dictates operating at a neutral pressure of a few tenths of a mtorr. However, large sheaths are undesirable because they limit the ability to implant recessed areas-ions accelerated by the average field in the sheath may not achieve the desired perpendicular angle-of-incidence on a sharply curved surface. This problem is considered in more detail in reference [7]. A planned upgrade of the modulator to three Litton L-5097 tubes, capable of providing $300 \mathrm{~A}$ pulses at up to $175 \mathrm{kV}$, will alleviate these constraints. 


\section{Experimental Results}

\subsection{Plasma density}

The plasma densities shown in Figure 2 are measured in the empty PSII chamber. When a conducting workpiece is present in the channber the plasma density is reduced near the workpiece, which serves as a recombination site. Typical radial plasma density profiles are shown in Figure 4 for the empty chamber and in the presence of a thin metal panel of width half the chamber diameter. Note that although the If antenna is above the panel, there is no appreciable shadowing of plasma density by the panel. This is important-it makes it possible to implant both sides of the panel if desired. This lack of shadowing is a consequence of the low operating pressure and low electron temperature (typically about $1 \mathrm{eV}$ ). The mean-free-path for electron impact ionization is longer than the chamber diameter, and electrons are reflected by the thin $\mathrm{rf}$ sheaths which exist around the grounded chamber surfaces. Therefore the plasma is produced as by a volume source. Many PSII experiments use a thermionic plasma source, which produces electrons with energies of 10's to 100's of electron volts. Due to the high energy of these electrons, magnetic bucket confinement is usually necessary at the chomber walls. No such confinement is necessary in the LANL facility. Some deposition of sputtered antenna material has been observed. This has not been considered to be a problem for the tribological applications being pursued at LANL, but could be prevented by installing a simple shield some distance below the antenna to interrupt the line-of-sight between antenna and workpiece.

\subsection{Sheath physics}

When a negative high-voltage pulse is applied to the workpiece, the electrons are very quickly pushed away so as to expose enough ions to shisld the plasma from the workpiece potential. Since the massive ions respond more slowly, a non-equilibrium sheath is iormed in which the ion density is initially unchanged from that which existed bciore the pulse. On a timescale of $1 / \omega_{p i}=\left(c_{0} M / n e^{2}\right)^{1 / 2}$, where $M$ and $n$ are the jon mass and density, the ions are accelerated toward the workpiece by the 
E-field in the sheath region. As the ions are accelerated, their density decreases, so as to conserve ion flux, eventually resulting in a space-charge limited flow of ions toward the workpiece. As the ion density in the sheath decreases, the electrons must move farther away from the workpiece (the sheath expands) so as to keep enough ions between them and the workpiece to shield the workpiece potential.

The sheath expansion away from a planar aluminum workpiece is shown in Figure 5. Note that higher $\mathrm{rf}$ powers (producing higher plasma densities) result in thinner sheaths, since the sheath need not move as far to uncover the number of ions necessary to shield the workpiece potential. The initial sheath expansion is faster than expected from published analyses $[8,9,10]$, because the sheath is expanding into an increasingiy dense plasma, as shown in Figure 4, rather than into the constant density plasma usually assumed.

This experiment operates at much higher pulse frequencies than achieved in other facilities-fast enough to consider whether the plasma can diffuse back into the depleted sheath region in between pulses. Figure 6 shows this effect in a temporal measurement of plasma density near the outer edge of the depleted sheath region following a high-voltage pulse. The low-voltage, low-density conditions presented here represent a worst-case for this experiment. From this and other measurements under these conditions, it appears that less than $150 \mu$ s is required to fill-in the sheath to its pre-pulse density. This value is in reasonable agreement with the ambipolar diffusion driven fill-in model proposed in reference [10], which predicts that this sheath should fill-in to $90 \%$ of its pre-pulse density in $250 \mu$ s, assuming $T_{e}$ and $T_{i}$ equal $1 \mathrm{eV}$ and $0.026 \mathrm{eV}$, respectively.

\subsection{Modulator voltage and current}

Modulator voltage and current traces are shown in Figure 7 for a $1 \mathrm{~m}^{2}$ cylindrical aluminum workpiece. This example will serve to illustrate several important points about the operation of the modulator. The implant voltage is set at the modulator voltage supply, but its rise-time is determined by the load represented by the expanding sheath around the workpiece. The two modulator switch tubes together 
will supply a maximum of $60 \mathrm{~A}$, although this is somewhat voltage dependent--in Figure 7 the peak current is seen to be about $46 \mathrm{~A}$. During a pulse, the modulator is initially current-limited, as the high density of ions uncovered by the retreating electrons near the workpiece are implanted. This high current loads down the modulator, depressing the voltage. As ions are implanted the load decreases and the voltage increases until it reaches its preset limit, here after about $5 \mu$ s. Due to the lower plasma density near the workpiece, shown in Figure 4, the voltage initially rises at a faster rate than would be expected from a constant-density analysis, since the lower density represents a smaller load. The decreasing current after $5 \mu \mathrm{s}$ is the space-charge limit of the expanding sheath.

A diverse combination of operating conditions are possible, but in practice the operating point is chosen by setting the voltage to the highest practical value, then adjusting the plasma density via the rf power to produce a voltage rise-time no longer than $5 \mu \mathrm{s}$, an empirical limit agreed upon by considering the power dissipation inside the switch tubes and the desire to implant ions at full energy. The "highest practical value" for workpiece voltage appears to be limited by workpiece arcing. Sparks are often seen near sharp edges when operating at high voltage. These sparks are assumed to be due to field emission into the plasma, since they do not appear to complete any electrical path to ground. Some arcing can be tolerated the modulator protect circuitry will "blank" (i.e. stop pulsing for $100 \mathrm{~ms}$ ) when an arc occurs, but if the arcing becomes too frequent the protect circuitry will shut down the modulator altogether. This may become a severe limitation when the voltage capability of the modulator is upgraded to $120 \mathrm{kV}$, but upgrading the peak current capability to $300 \mathrm{~A}$ should help.

\subsection{Secondary electron emission and $x$-ray production}

When an ion is implanted in the workpiece, a number $\gamma$ of secondary electrons are emitted. The value of $\gamma$ depends upon the material, and generally varies the square root of the implant energy. A comparison of actual implanted dose to the anticipated dose suggests values of 5 for steel and 10 for aluminum are reasonable at the voltages typically used in this experiment. These secondary electrons are accelerated away 
from the workpiece by the applied voltage, forming a current which must be supplied by the modulator. This is a serious inefficiency in the PSII process-- for an aluminum target only about $9 \%$ of the modulator current represents implanted ions. The high energy secondary electrons are essentially collisionless in the plasma, and so deposit their energy into the walls of the PSII chamber, creating $x$-rays. Measurements outside an unshielded pyrex port show that the $\mathrm{x}$-ray flux increases steeply with secondary electron energy, as shown in Figure 8. Modeling of the $\mathrm{x}$-ray emission and shielding requirements using the Monte Carlo code MCNP [11] has shown that the $1 / 2$ inch stainless steel walls of the PSII chamber provide adequate shielding at $60 \mathrm{keV}$, but that lead shiclding around the chamber will be required at $100 \mathrm{keV}$ [12]. Results of $x$-ray monitoring using thermoluminescent devices (TLDs) around the PSII chamber are consistent with the $60 \mathrm{keV}$ modeling. A proposal for using a magnetic field to insulate secondary electrons from the high field region, thereby increasing the efficiency and reducing $x$-ray flux, is described in reference [13]. Experiments to test this concept are being performed on the LANL PSII facility.

\subsection{Workpiece and chamber heating}

Due to the high currents and pulse frequencies run in this experiment, workpiece heating is problematic. Nearly all other PSII experiments actively cool the workpiece with water or oil, however the design and installation of cooling for the multitude of small workpieces being implanted in the LANL PSII facility is a difficult engineering problem which is still being addressed. A $50 \mathrm{kV}$ implant with $20 \mu \mathrm{s}, 35 \mathrm{~A}$ average current pulses at $500 \mathrm{~Hz}$ generates $17.5 \mathrm{~kW}$, all of which is eventually deposited as heat in the workpiece or PSII chamber walls. Due to the high secondary electron coefficient, most of the energy ends up in the walls. Indeed, the chamber wall heats up to about $80^{\circ} \mathrm{C}$ during an implant. At present power levels the chamber is relatively easy to cool using forced air. Keeping the workpiece cool is more difficult. Since it is under vacuum, there is no heat loss mechanism (radiation is far too weak at acceptable workpiece temperatures). The actual temperature rise is easily calculated as a function of implant dose, knowing the implant area, workpiece volume, and the 
density and specific heat of the material. Setting an upper workpiece temperature limit of $200^{\circ} \mathrm{C}$ often requires implanting a typical $5 \times 10^{17} \mathrm{~cm}^{-2}$ dose in two or three sessions, allowing the workpiece to cool in between. The required cooling can be accomplished in about 3 hours by filling the PSIl chamber with helium to 10 torr. Higher pressures would be more efficient, but are costly due to the large volume of the PSIl chamber. This convective cooling is only an interim solution until an active cooling system is designed and installed.

\section{Summary}

A large-scale PSII facility has been assembled at Los Alamos National Laboratory in which workpieces of area greater than $4 \mathrm{~m}^{2}$ have been implanted. Despite the $50 \mathrm{~A}$ currents available from the high-voltage modulator, this experiment is still currentlimited due to the large implant areas. A future modulator upgrade to $300 \mathrm{~A}$ peak current should partially alleviate this problem, and also help the modulator absorb field emission arcing when the voltage capability is upgraded to $120 \mathrm{kV}$. Workpiece heating is a limitation at present, but more efficient cooling is being designed. Secondary electron emission is a basic inefficiency of PSII and produces $x$-rays which can be a health hazard. Magnetic insulation of the workpiece is being investigated as a way to mitigate these problems. Lead shielding is also being installed. It is the goal of this experiment to demonstrate that PSIl can be scaled-up to an industrially useful process.

This work has beew performed as part of a Cooperative Research and Development Agreement (CRADA) between Los Alamos and General Motors. It is supported by the U.S. Department of Energy Defense Programs Technology 'Transfer Initiative. 


\section{References}

\section{References}

[1] J. R. Conrad, J. Appl. Phys. 62, 777 (1987).

[2] J. R. Conrad, J. L. Radtke, R. A. Dodd, Frank J. Worzala, and Ngoc C. Tran, J. Appl. Phys. 62, 1591 (1987).

[3] J. R. Conrad, Mat. Sci. Engr. A116, 197 (1989).

[4] W. A. Reass, Proc. IEEE Pulsed Power Conf. (1993).

[5] W. A. Reass, J. Vac. Sci. Tech. (thie issue).

[6] R. J. Gribble, Proc. IEEE Pulsed Power Conf. (1993).

[7] R. J. Faehl, B. G. DeVolder, and B. P. Wood, J. Vac. Sci. Tech. (this issue).

[8] J. T. Scheuer, M. Shamim, and J. R. Conrad, J. Appl. Phys. 67, 1241 (1990).

[9] R. A. Stewart and M. Lieberman, J. Appl. Phys, 70, 3481 (1991).

[10] B. P. Wood, J. Appl. Phys. 73, 4770 (1993).

[11] J. F. Briesmeister, Los Alamos National Laboratory Report LA-7396-M, (1990).

[12] B. P. Wood, J. T. Scheuer, M. A. Nastasi, R. H. Olsher, W. A. Reass, I. Henins, and D. J. Rej, MRS Symp. Proc. 279, 345 (1993).

[13] D. J. Rej, B. P. Wood, R. J. Faehl, and H. H. Fleishmann, J. Vac. Sci. Tech. (this issue). 


\section{Figure Captions}

Figure 1. The Los Alamos PSII chamber.

Figure 2. $\mathrm{N}_{2}$ plasma density along chamber axis vs. applied $\mathrm{rf}$ power.

Figure 3. The Los Alamos PSII high-voltage modulator.

Figure 4. $\mathrm{N}_{2}$ plasma density vs. radial position, with and without a $0.75 \mathrm{~m}$ wide metal sheet, at 0.2 mtorr and $200 \mathrm{~W}$ rf power.

Figure 5. Sheath propagation for a $0.8 \mathrm{~m}^{2}$ per side planar aluminum workpiece, pulsed with $33 \mathrm{kV}$ at $10 \mathrm{~Hz}$, in 0.18 mtorr $\mathrm{N}_{2}$.

Figure 6. Density $40 \mathrm{~cm}$ from the workpiece in Figure 5, as a function of time following $500 \mathrm{~Hz}, 23 \mathrm{kV}$ pulses in a 0.11 mtorr, $100 \mathrm{~W} \mathrm{rf} \mathrm{N}_{2}$ plasma. Dotted line is the plasma density with no pulses applied.

Figure 7. Modulator voltage and current into a $1 \mathrm{~m}^{2}$ cylindrical aluminum workpiece, at $300 \mathrm{~W}$ rf power and 0.35 mtorr $\mathrm{N}_{2}$.

Figure 8. X-ray flux vs. secondary electron energy. 


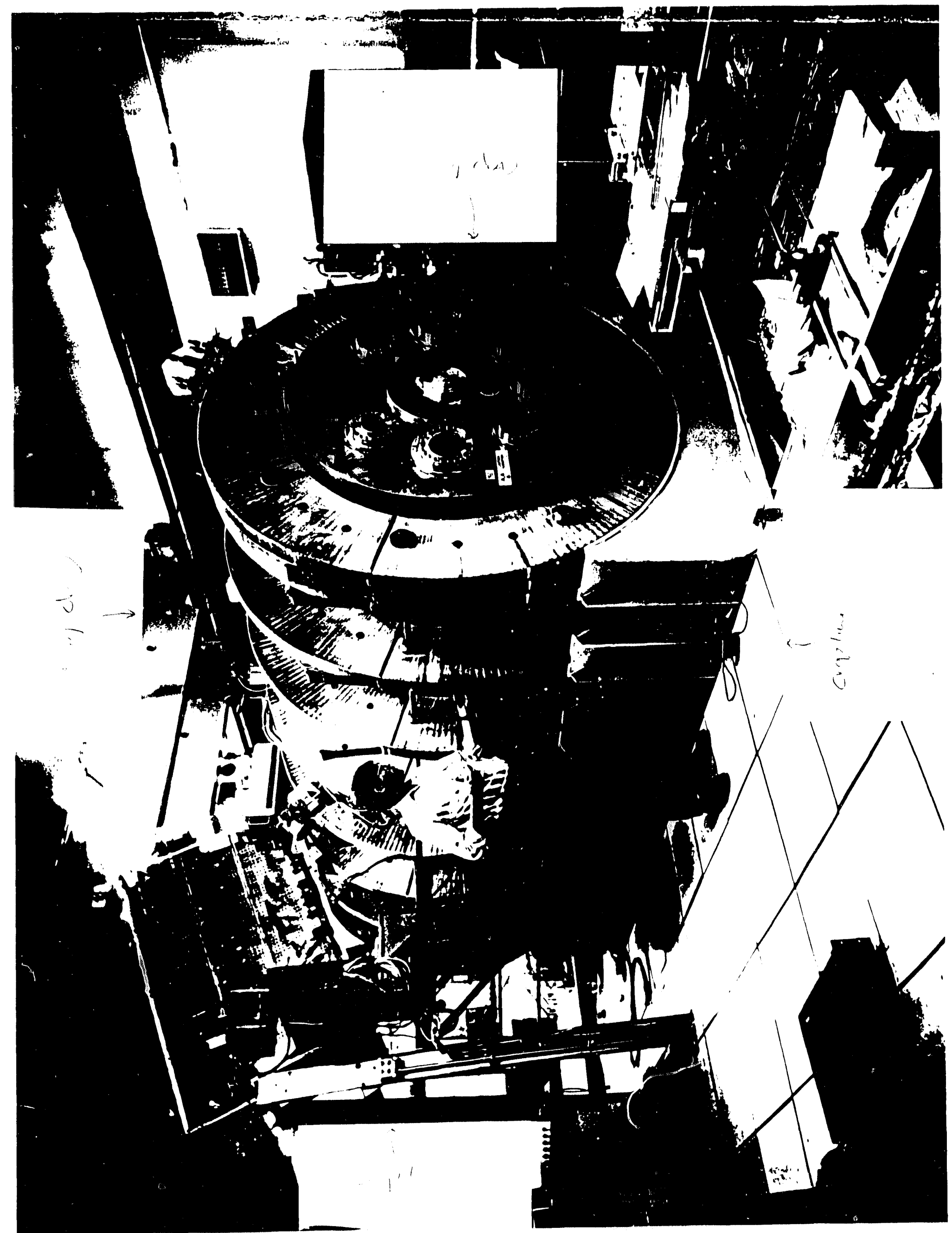




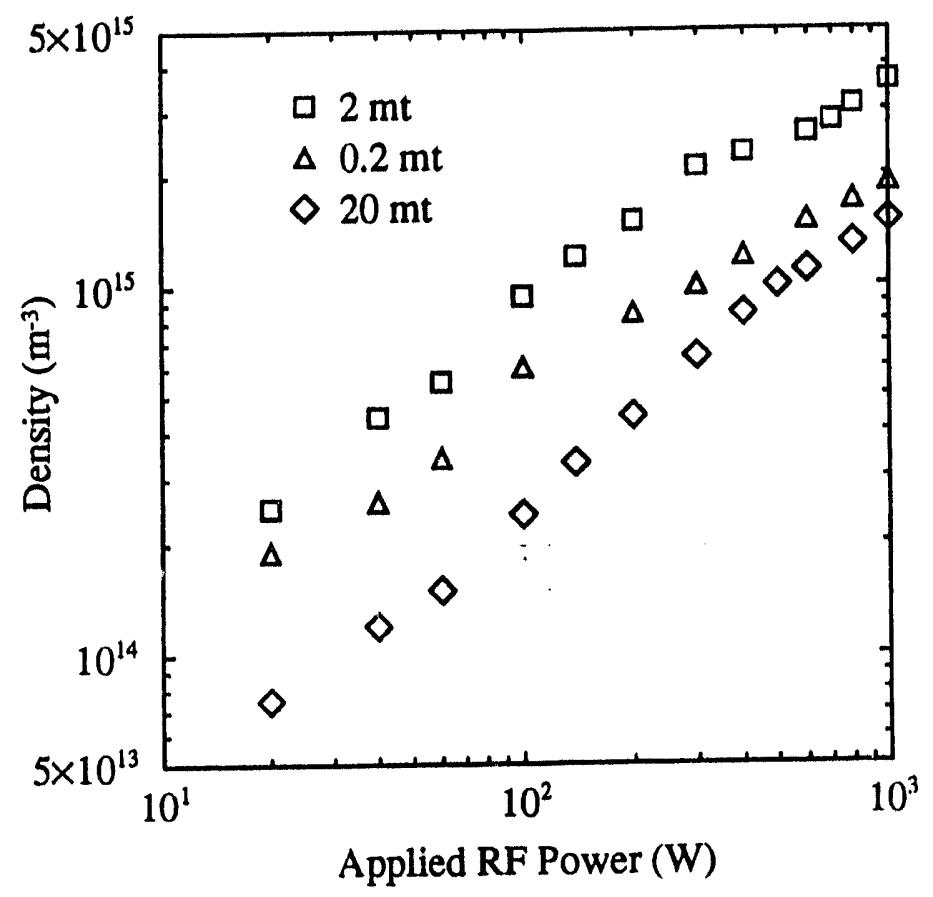




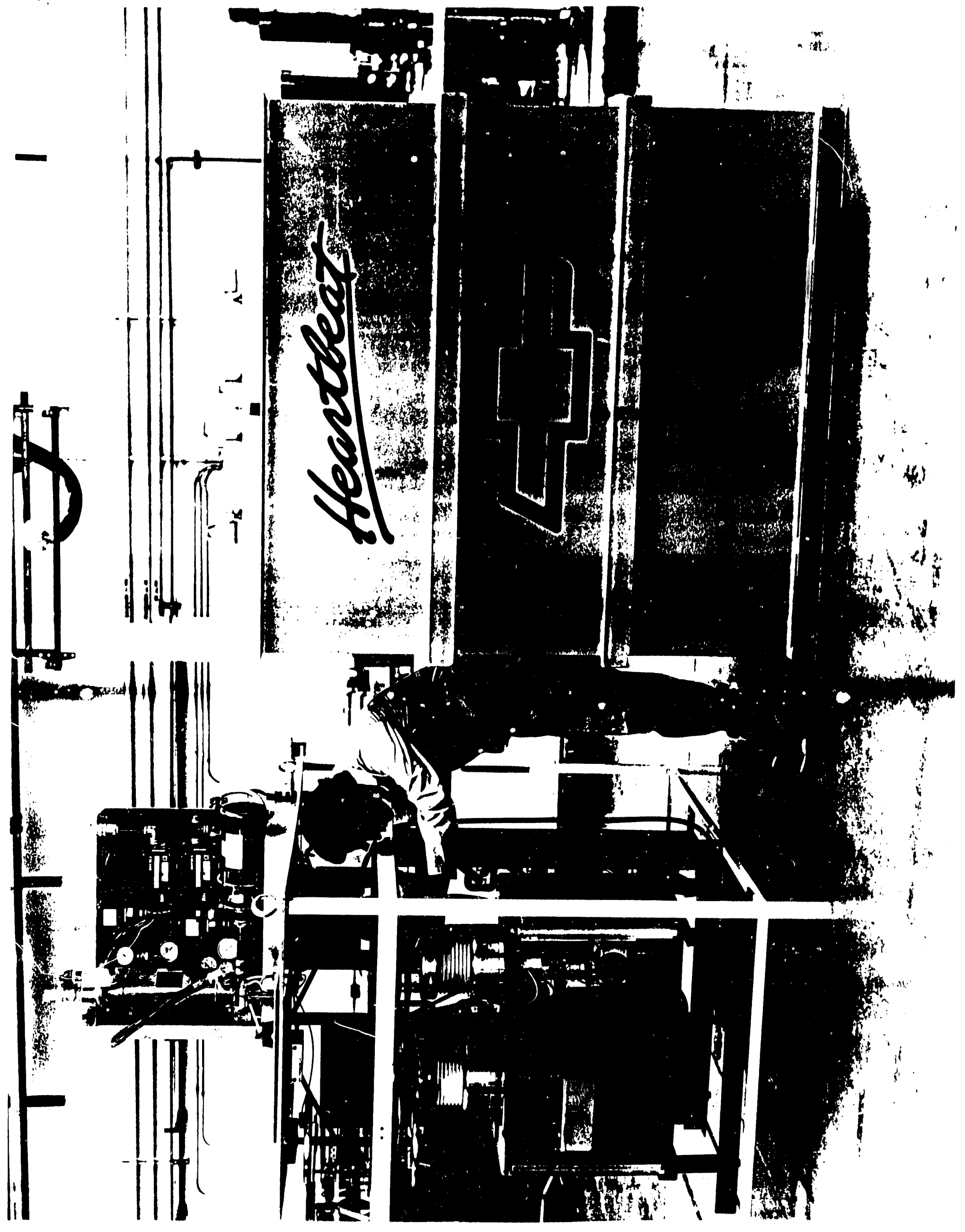




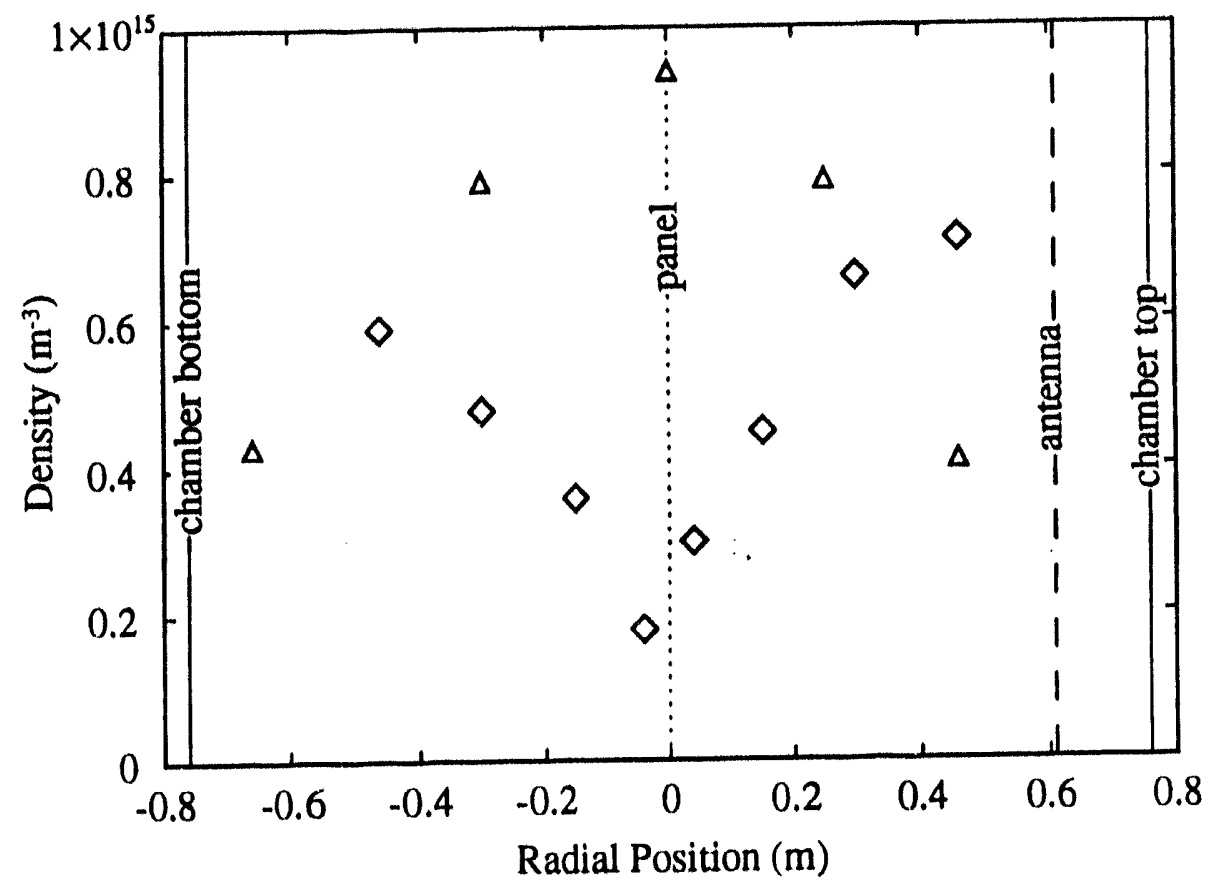




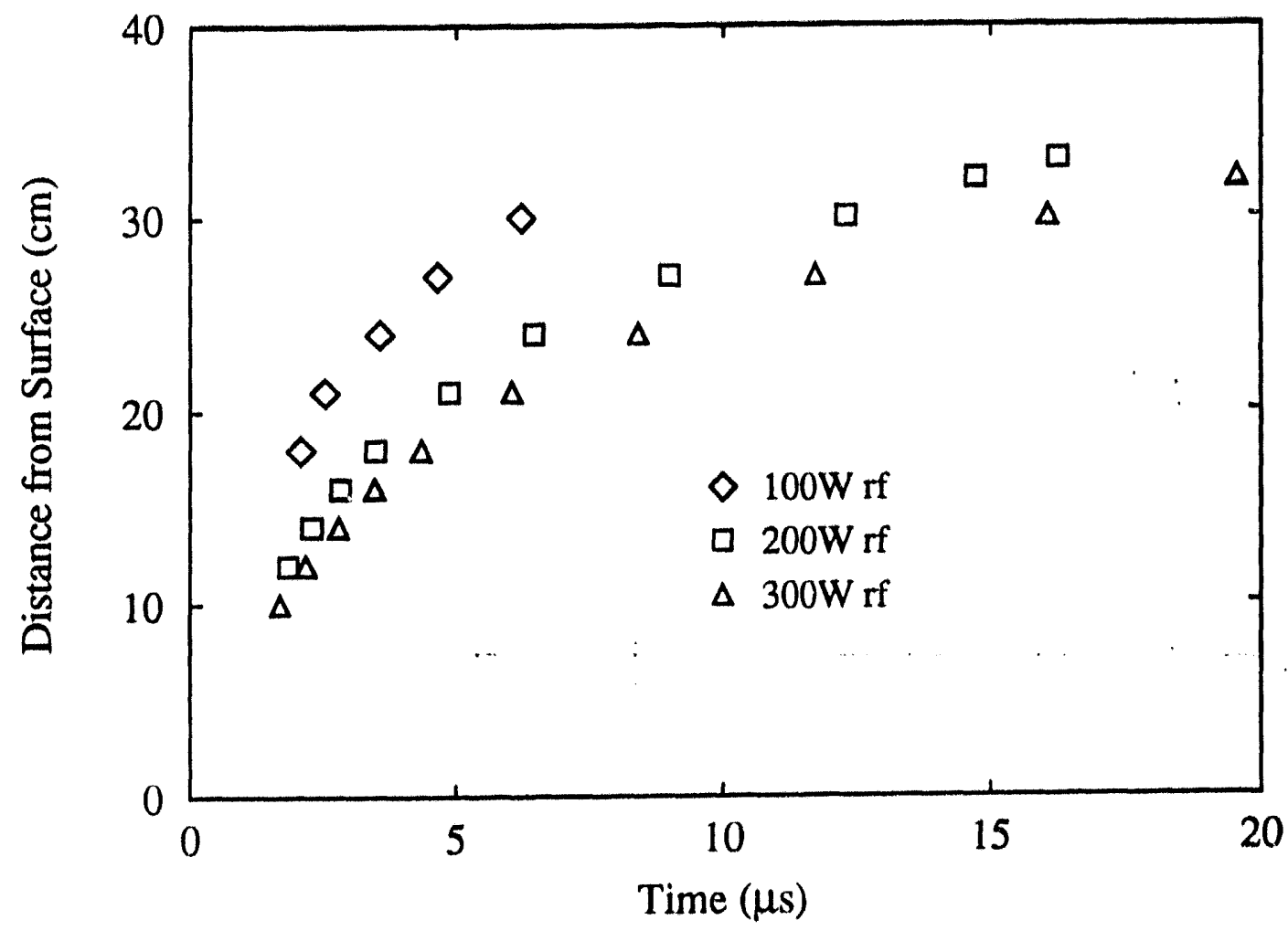




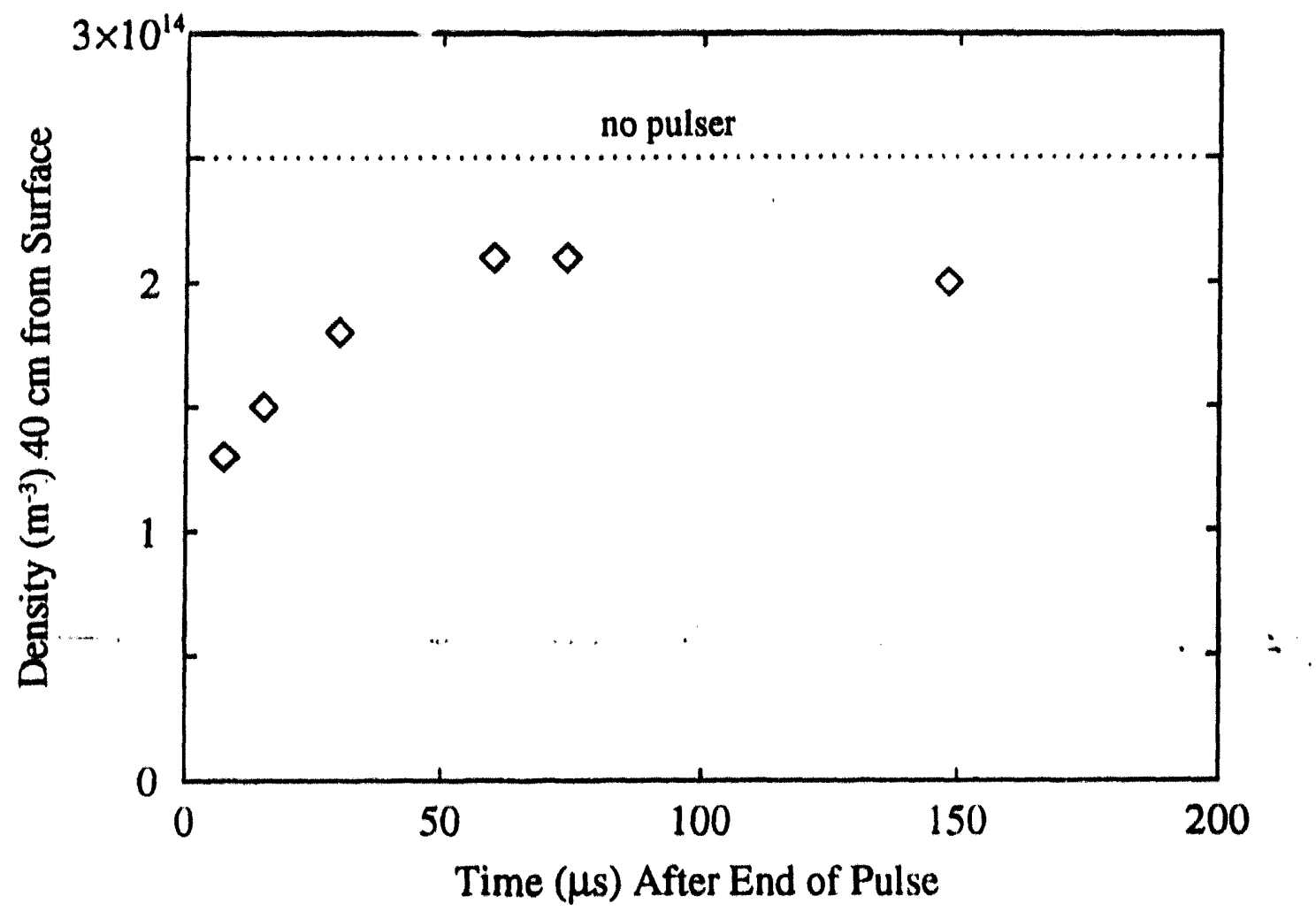




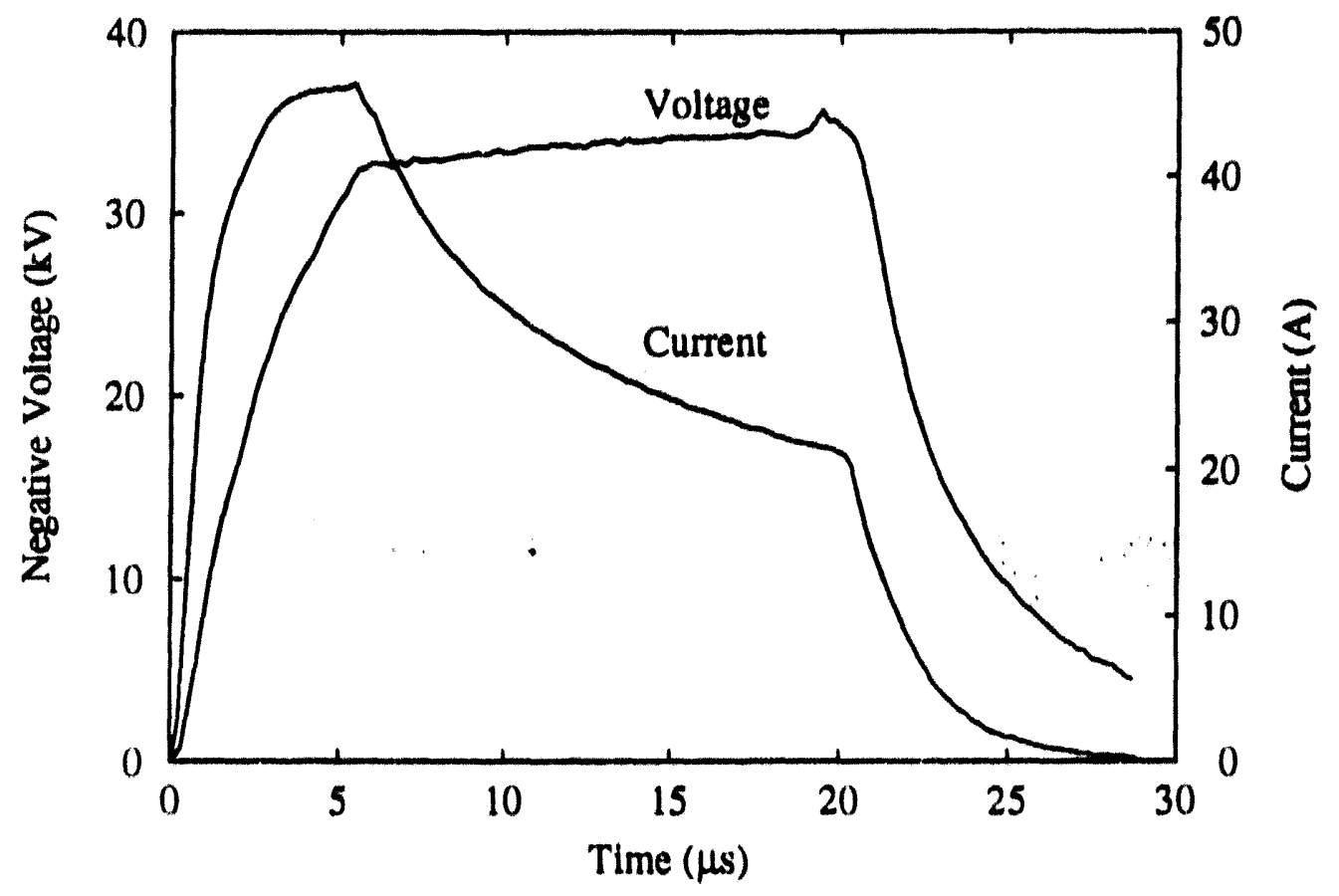




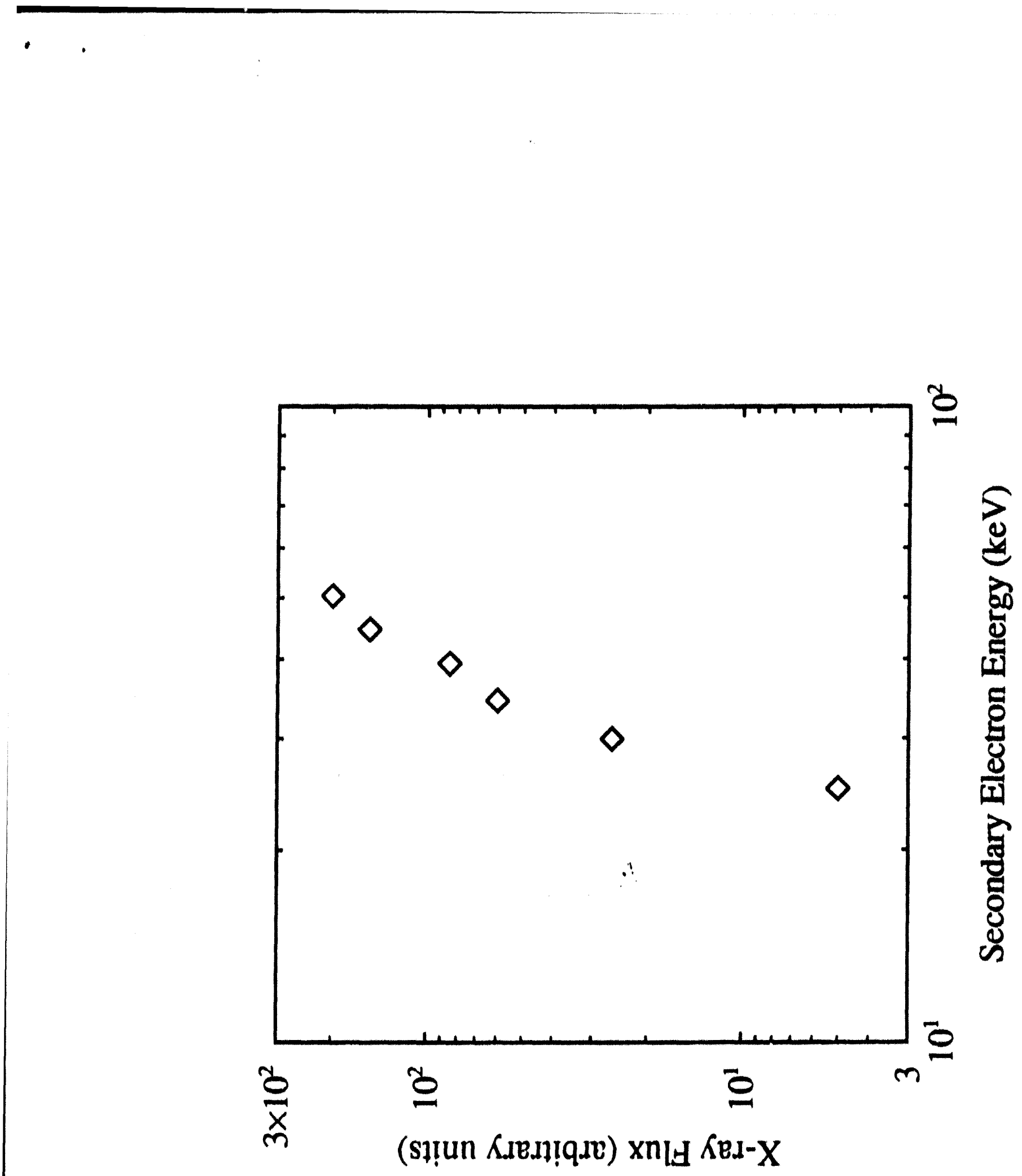





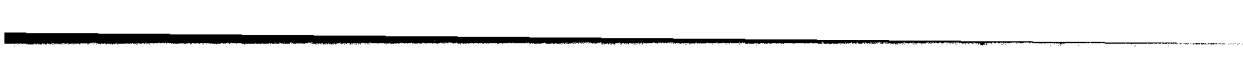

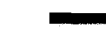

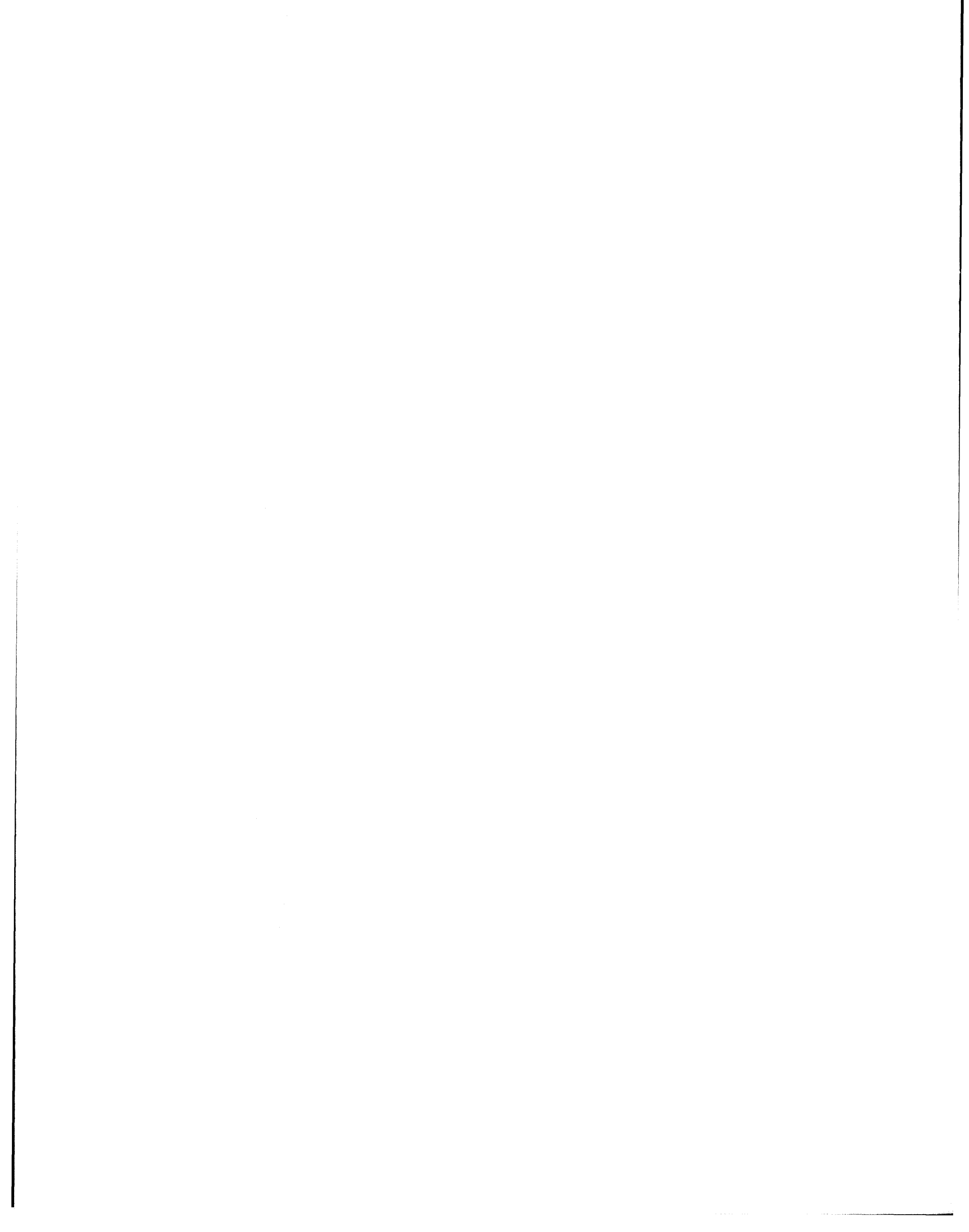

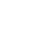

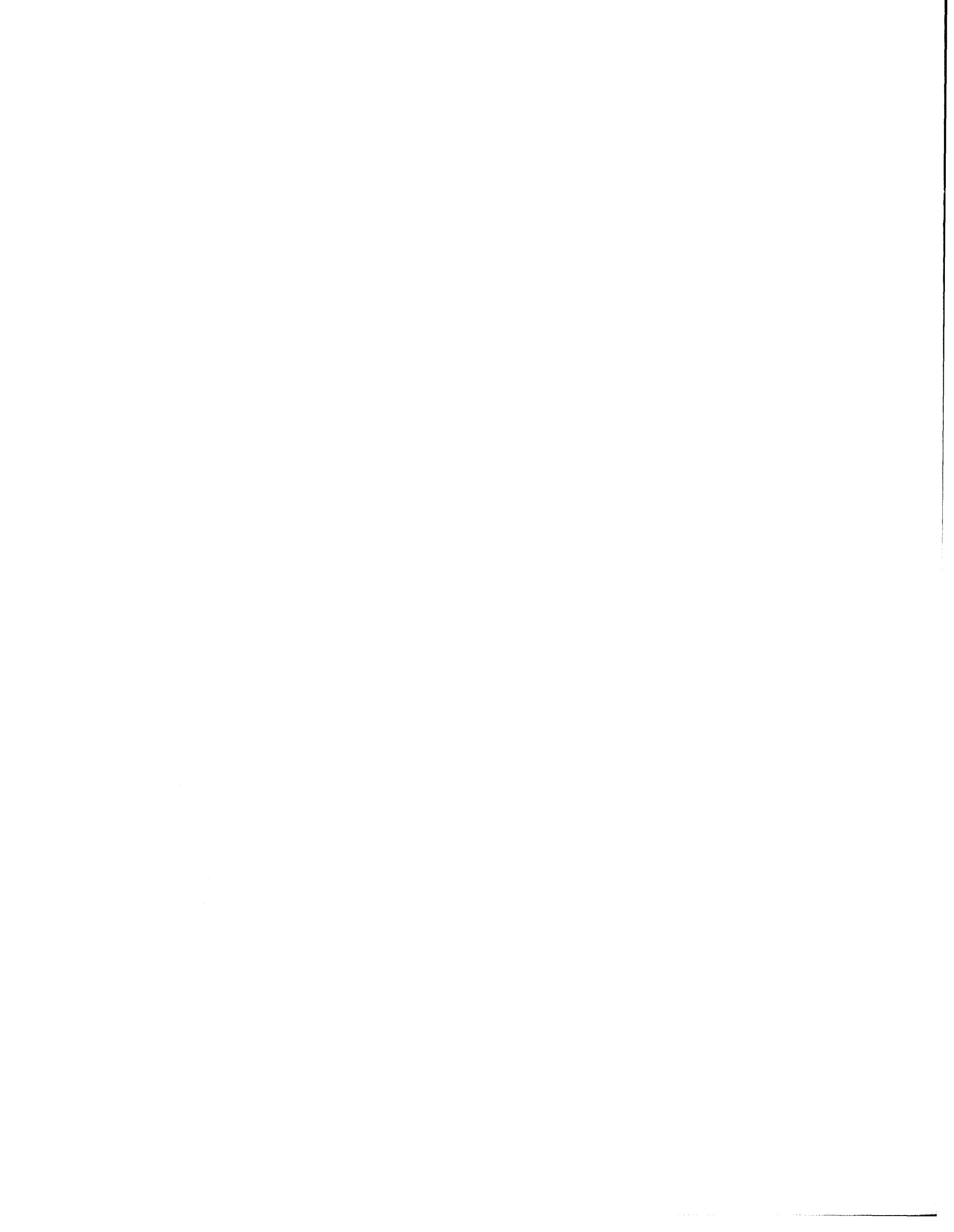

